\title{
Socio-Religious and Legal Perspectives on Women Health in Pakistan
}

\author{
${ }^{a}$ Nauman Reayat, ${ }^{\mathrm{b}}$ Anwarul Mujahid Shah, ${ }^{\mathrm{c}}$ Neelam Farid \\ ${ }^{a}$ Department of Political Science, Abdul Wali Khan University, Mardan, Pakistan. \\ Email: nauman381a@gmail.com \\ ${ }^{\mathrm{b}}$ Department of Sociology, Political Science and Education, Bacha Khan University, Charsadda, Pakistan. \\ Email: anwar_ids@yahoo.com \\ ${ }^{c}$ Department of Sociology, International Islamic University, Islamabad, Pakistan. \\ Email: neelam.farid@iiu.edu.pk
}

\begin{tabular}{l}
\hline ARTICLE DETAILS \\
\hline History: \\
Accepted 23 Feb 2021 \\
Available Online March 2021 \\
\hline Keywords: \\
Sexual Health, Fertility Issues, \\
Reproductive Capacity \\
JEL Classification: \\
K32, K39
\end{tabular}

DOI: $10.47067 /$ real.v4i1.105

\begin{abstract}
This paper focuses on the sexual health of women and their counteractive action practices against cancer. Steady with acknowledged definitions, inside the extent of this exploration, women's sexual wellbeing envelops regenerative wellbeing and fruitfulness and the physical, mental, enthusiastic what's more, cultural and social betterment identified with sexuality during a life of an individual. Albeit sexual wellbeing is a phenomenon which is extremely personal to an individual, it is basically impacted by different factors including the personality of an individual, kind of family to which individuals belong, group of friends and peers in which individuals live, and the state laws to which individuals are subjected. These factors are beyond individuals' control. Other than physical, mental and subjective markers, sexual wellbeing is influenced by political and monetary variables, standards, parts, social qualities, and religious convictions. This article, reflecting on the sexual health of women, presents information generally from creating nations. Also, it provides a circumstantial examination of reproductive tract infections (RTIS) and an understanding of contraceptives' uses in Pakistan. Further, this paper reflects upon on socio-religious context of Pakistan that affects data on sexual wellbeing. This paper's important contribution is to provide a survey of the integrative model of conduct expectation (Fishbein, 200o) and provide socio-religious and legal perspectives on women sexual health.
\end{abstract}

(C) 2021 The authors. Published by SPCRD Global Publishing. This is an open access article under the Creative Commons AttributionNonCommercial 4.0

Corresponding author's email address: anwar_ids@yahoo.com

\section{Overall Socio-Religious Perspective}

The more extensive socio-cultural setting assumes a huge part in an individual's life. This setting affects individuals' sexual inclinations and practices. Lorimer (1954) recognized just about sixty years back that there are different essential of effective family planning activities. One of these essentials of 
effective family planning activities is thinking about the "foundation conditions" that aide practices. Additionally, Freedman (1987) accentuated the significance of social impacts on issues identified with concepts like family planning, its control and fertility, characterizing society as "the arrangement of convictions that guide conduct in every general public.

In Pakistan, there is a strong relationship between society and religion. This relationship characterizes the central qualities and regulating conduct designs in the general public. Islam is not thought to be just an adorable, in addition to a social framework, a society and a human advancement (Omran 1992).

Along these lines, in a preservationist nation like Pakistan where a large part of the population is religious in their public life, religion extraordinarily impacts all regions in life, including different aspects of health. Islam recognizes different dimensions of individuals' sexual desire and is mindful of the sexual inclination and craving for a continuation of human generation. Had it not been the case verses about forbidden and allowed the relationship between a man and woman would not have been there in the Quran in the first place. However, it is generally believed among those who follow Islam that sexual identity is something given by god (Halstead and Lewicka, 1998). Generally, Islamic principles encourage and appreciates sexual relationship inside the contract of marriage. It considers marriage to be a protective shield from improper sexual conduct like sexual interaction without marriage. Therefore, as implied in religious texts of Islam, a family is the fundamental unit of society, and the development of a family is a vital obligation of couples raising the family.

As Pakistani culture vehemently emphasizes on protecting young girls' virginity before the beginning of marital life, it is an element that significantly influences the process of women' education, age fitness for marriage, self-sufficiency and portability (Bott and Jejeebhoy, 2003). Virginity is a sensitive topic and seen by many in Pakistan as an indicator of the family's honour. Women guardians secure virginity by utilizing any methods available to them. Ensuring that their little girls save their virtue before marriage, guardians take extra care in making it sure that their young kids should not go outside homes unaccompanied by their family members. Regularly izzat (honour) is secured by honing purdah (to escape sight) standards after immaturity and adolescence. It mainly requires separation between physical and social spheres of genders lives (Khan, 1999; Bott and Jejeebhoy, 2003; Khan, 2000; Hardee, Pine, and Wasson, 2004;). In any case of women violation of social standards and her relationships having been discovered or even perceived to have a sexual relationship, she can be eliminated or executed by laws. Or she can be charged for extra-marital relations under the Huddod Ordinance 1979, which may prompt detainment or death(Khan, 2000).

Whenever wedded, absence of self-sufficiency in homes after marriages frequently incorporates youthful females' restricted chances to take an interest in the choices about their own particular wellbeing and family long-term or short-term planning (Bott and Jejeebhoy, 2003). In South Asian society, relatives of marital partner(in-laws) anticipate that relational unions will lead to the birth of a child in a couple of years of marital partners begin to live together in a household (Adhikari, 2003; Chowdhury, 2003). In tradition societies, large number of children is perceived as socially and financially advantageous. Male children are seen as a symbol of pride by family elders because males are considered as breadwinners of a family. Farsoun et al (1996) offered an appraisal by distinguishing three social boundaries that played an important role in controlling the problem of the increase in population of Jordan. Same logic is applicable to other countries where religion or traditions dominate (Al-Oballi Kridli and Libbus, 2001). The state of Pakistan is included in these kinds of countries. The first social marker is the predominant perception about males as breadwinners. It has been inculcated 
in society over time that only males are able to work for the family and hence, can make a living for whole family. Further, elders in family perceive male children as those upon whom they can rely when elders are ill and need care in their last phase of life. Also, there is familial weight to give birth to more and more children, particularly boys, keeping in mind the end goal to safeguard the family name. The third marker is rooted in religious obligations. It is generally believed by Muslims that the religion Islam require them to duplicate and multiply the earth. This multiplication makes Muslims productive. Moreover, people should not see more number of children as a burden on their families. Allah created them and he will deal with kids (Ibid).

Family planning is an extensive approach to sexual wellbeing and is significantly affected by religion. In any case, the elucidations of the Quran with respect to whether Islam permits contraceptives is questionable. There is no consensus among Muslim scholars and nations over the issue of family planning (Seltzer, 2002) because of a wide variety of interpretations and translations of religion and locally observed social customs. Different religious cholars hold different views but some religious experts suggest that that al-azl (intercourse interruptus or the technique of withdrawal) as an aversion of pregnancy is admissible in Islam, and correspondingly current optional techniques are permitted if the ultimate objective is to forestall pregnancy without bringing about perpetual loss of capacity to reproduce and fertility (Omran, 1992). In any case, for quite a long time, religious concerns have been among the two major explanations behind restraining from use of those measures and methods that can avoid pregnancy (Casterline, Sathar, and Minhaj ul Haque, 2001). A few Muslims do not appreciate the use of anti-conception medication instead of using contraceptives. They view a certain degree of a clash between the use of anti-conception medication and their moral standards (Hardee and Leahy, 2008). They believe that God creates and destroys and hence, any kind of control must be dictated by God's will. This belief is shared by many that religion discourages the use of contraceptives. It is this widespread belief which motivates many to associate higher religiosity with greater family sizes of Muslim communities. (Siddh, 1974).

Many Muslim nations including but not limited to Bangladesh, Iran, Egypt, Indonesia took different steps to remove any kind of association between religiosity and large family sizes. They and have successfully secured the support of Islamic religious heads to get control over the increase in population through different projects of family planning. Indeed, even in a country like Pakistan where religion and culture together dominate social behavior, different social groups and well-known religious figures held joint activities to increase awareness about the use of contraceptives in light of Islamic principles (UNFPA, 2008). Nonetheless, such coordinated effort is frequently convoluted. According to one survey conducted among Muslim scholars in Pakistan, just 9\% of the selected sample of Muslim scholars in Pakistan came up with the response that Islamic principles endorse the approach of family planning and $43 \%$ of the selected sample see that Islam discourages any kind of family planning (Hakim, Hussain, Baqai, and Tanweer, 2000). Along these lines, drawing nearer this point from the religious perspective may have an inverse impact. As indicated by Hoodfar and Assadpour's study (2000), numerous religious pioneers discredit family planning during their sermons of Friday prayers. They rebuke the use of contraception by couples with a "western plot" aimed at oppression of Muslims and keeping up the strength of the West over the Islamic nations.

\section{Legal Perspective}

Pakistan is an Islamic republic. The structure of its state of Pakistan is Islamic. The laws in Pakistan and justice system are vigorously affected by Islamic legal principles, which likewise controls fields identified with sexual wellbeing. Truth be told, Islamic law gives clear guidelines to Muslims' sexual conduct. As indicated by the Hudood Ordinance enacted in 1979, sexual intimacy in Pakistan is 
legitimate exclusively in marriage settings between a couple. Under the Islamic precepts, for a girl to become a woman requires onset of the monthly cycle and hence by this logic and along these lines engaging in sexual relations before marriage are subject to extreme discipline (Khan and Pine, 2003)

A frank and open discussion of the topic of sexual health may have different implications for political future of politicians in Pakistan. Since there are some religious restrictions over this issue of sex and also that parliamentarians fear to lose votes and popularity, a very limited number of health experts and non-governmental organizations openly and frankly discuss the topic of sexual health (Hardee, Pine, and Wasson, 2004). International Conference on Population and Development (ICPD)(United Nations, 1995), signed by Pakistan, which among different themes touches upon sexual health issues among youths and grown-ups. Chapter eight of ICPD clearly stipulates that full consideration should be given to advancing commonly deferential and fair sex relations and sorting out the instructive and administration needs of youths to empower them to bargain in a useful, healthy and mindful direction sexual orientation (Ibid). It drew attention of all stakeholders to different problems such as adolescent sexual and regenerative health problems, including undesirable pregnancy, dangerous fetus removal (as characterized by the WHO, and HIV/AIDS and other sexually transmitted diseases (STDs), are attended through the advancement of capable and sound reproduction and sexual conduct, along with willful restraint, and the procurement of proper delivery of services and guidelines particularly appropriate for that age range(Ibid). These steps are aimed at achieving different objectives. The first objective is to advance the sufficient improvement of mindful sexuality that grants value and shared appreciation between the sexes. The second objective is to guarantee that men and women have access to data. The third objective is the provide access to training and administrations expected to accomplish great sexual health and activity their rights and obligations about reproduction (Ibid).

Prescribed activities incorporate offering backing to basic sexual awareness and services for youngsters and additionally to create national arrangements that would consider the substances of existing sexual practices (United Nations, 1995). Be that as it may, Pakistan adopted a strategy different some other Muslim nations. The national strategies adopted by the government of Pakistan have not moved its attention to youngsters' sexual wellbeing issues. The governmental strategy did not pay attention to suggestions and propositions explained in the ICPD. National Population Policy, attempting to establish a population-control regime, was formulated in Pakistan in 2002.

Pakistan Ministry of Population Welfare (2002) clearly stated that youth constitutes the future of the nation and should be sharpened about the far-reaching outcomes of quick populace development for the single, married, family and country and, in this manner the need to construct an outlook for mindful parenting style. The two-dimensional procedure deals with youths through populace and awareness about family life through different kinds of education including mainstream formal education and informal parts of education (Ibid). Further, the approach connects with youthful couples with fitting media, interactive messages and delivery of services

The World Bank Report 2011 suggests that high suspension in preventative use may lead to increasing maternal and child death rates as. It also gives rise to abnormal amounts of undesirable fertility represented by the figure of 900,00o spontaneous abortions annually (Sathar, Singh, and Fikree, 2007). Besides, sexual wellbeing awareness concentrating on sexually transmitted infections (STIs). This included HIV counteractive action, is not secured in this record.

The Government of Pakistan endorsed another National Population Policy in 2010. The plan 
made family planning projects more organized and integrated (Pakistan Ministry of Population Welfare, 2010). In addition to these efforts, the Ministry of Population showed its commitment towards the implementation of ICPD goals. The Ministry expressed it willingness through its Secretary to set out the objectives taking after three noteworthy ranges of the ICPD. The Secretary expressed his willingness in an announcement on the platform of Commission on Population and Development. Nonetheless, this report, does not notice sexual training of youths or unmarried youthful grown-ups in its arrangement of activity (Durrani, 2010).

Under the eighteenth constitutional amendment, Pakistan Ministry of Population Welfare was shifted to the jurisdiction of the provincial government for operation and function from December 1, 2010. Following such shift, provincial governments took over all subjects concerning health-related projects. This step created obstacle in making synchronized endeavors, departmental approaches, and inter-departmental cooperation - variables whose low frequency has effectively constrained Pakistan's advancement in regenerative and sexual wellbeing improvement (Abrejo, Shaikh, and Saleem, 2008). This change could then diminish the formality and give more open doors for a coordinated effort between nongovernmental associations and locally administered governments for improving new sexual well-being awareness programs.

\section{Socio-Cultural and Health of Women in Pakistan}

Pakistani society is a tradition society. It has conservative and rigid socio-cultural standards. These standards directly affect movement of young females. Young females cannot move independently and freely in society. They usually need a male guardian to move freely. Under these circumstances, any discussion of sex in general and sexual health in particular is almost impossible for women. Since they cannot talk about their sexual health, it is difficult for them to improve their sexual health. Moreover, social and religious guidelines limit Pakistani young females' ability to use the services of health clinics. Since elders consistently look after their kids and keep an eye on them and intervene when sexual behavior of youngsters go out of line, the versatility of unmarried energetic adults is under control. The outcomes of a public review report in Pakistan proffers that $96 \%$ of energetic females required unequivocal approval to visit wellbeing focuses arranged locally, while 87\%, despite when permitted, were not allowed to visit wellbeing encouraging establishments alone (Sathar et al., 2003). Besides, male guardians of any family usually feel less inclined to take their adolescents to nearby health services even when adolescents are in basic need of sexual health services. These elders are perplexed this could be viewed as a sign that their youngsters are sexually developing which could imperil family reputation (Khan, 1999).

Marriages have less impact on women life. No significant change can be observed in restrictions over women mobility and freedom after their marriages. Since Pakistani society is patriarchal in nature, men have huge control over the access of family members to health facilities. For instance, an efficient survey showed that in the province of Punjab, just $28 \%$ of wedded females were permitted to access health centres without the company of their male family members or guardians (Jejeebhoy and Sathar, 2001). There are other academic works suggests that there are different reasons for women' declining interest in study of topics related to sex (Raza et al., 2010). However, one of the principal reasons why girls have declined to take an interest in studies that involve questions and answers sessions about sex is the refusal of prior permissions to them by their husbands (Raza et al., 2010).

In any case, even in families where girls enjoy more freedom of movement, expression and association, the individuals who have a need to visit a health specialist regularly attempt to take care of their issues on their own or with the assistance of their companions or relatives (Mouli, 2003). 
Different surveys have been conducted on this issue. A national survey in Pakistan showed that more than seventy-five percent of 15 to 24 olds don't counsel a specialist either because they think that their health problems are either too general or too complicated to be attended (Faizunnisa and Ikram, 2004). Moreover, even when looking for medicinal services, young citizens living in urban Pakistan suffering from health problems want to look for it in a locally situated "sex clinic" where delivery of services is ensured by homoeopathic specialists (hakeems). These hakeems regularly work unlawfully and don't have medicinal expertise (Ranjha and Hussain,2003). For some youthful people, these are frequently these clinics main spots to consider as they are seen to be less judgmental contrasted with general health centres. In any case, the nature of consideration gotten from these offices is frequently unsatisfactory. Ranjha and Hussain (2003) carried out a survey among hakeems or homoeopathic specialists in various areas of Rawalpindi district, Pakistan. Analysing the collected data, they concluded that the healers had unreliable, unhealthy, myth-ridden, and incorrect information about sexual wellbeing. According to survey report, respondent's awareness about sexual health issues was limited as they had constrained and frequently wrong data about STI analysis and medications. This issue was visible in their struggle with finding words to explain sexual wellbeing issues. Additionally, the recommended prescriptions regularly contained unsafe substances as ravenous stimulants, irrelevant hormones and opiates. Patients different issues and problems about hakeems one of which was the latter's in appropriate behaviour (Ranjha and Hussain, 2003).

There are numerous pragmatic obstructions and shame and social imperatives that bring youthful Pakistani females' connectivity with health facilities or responsible and safe sexual activities. Barnett and Schueller (2000) provide a good understanding of this phenomenon by explaining that impediments for youngsters to look for social insurance give rise to different problems. First, it incorporates the high cost of service-delivery to them. Second, they get badly designed areas or working hours. Third, they fail to visit a health specialist without the consent of their elders or family guardians. Case in point, current laws in Pakistan encourage and prefer permission of parents or state for HIV testing of teenagers under the age of eighteen (Khan and Khan, 2010). Additionally, life style is another important factor of sexual behavior. Living statuses of youthful females may have an impact on their sexual practices. Case in point, as in Pakistan generally unmarried youngsters live with guardians. They fear being judged and consequences of being observed using or found having contraceptives (Hardee, Pine, and Wasson, 2004). This fear about negative reaction from family elders and society at large discourages and stops them to risk using contraceptives.

Moreover, for some youthful people going to health facilities is not adequate due to privacy issues with a medicinal services supplier, debilitating and judgmental facility staff individuals, apprehension of medicinal methodology, sentiment disgrace and humiliation (Senderowitz, 1999), additionally, above all, apprehension of revelation by group or relatives (Barnett and Schueller, 2000; Capoor and Patel, 2006). These can be gruesome hindrances for a youngster to find health care, particularly in the event that it is identified with touchy points, such as sexual well-being or female tumour counteractive action. For example, 56\% of youthful unmarried female Karachites expressed that STIs or issues identified with sexual organs ought not to be accounted for to anybody (Ali, Ali, Waheed, and Memon, 2006).

Finally, under-capability of human services suppliers can likewise be a hindrance for social insurance looking for. Enlistment and preparing very much qualified human services suppliers is frequently risky in creating nations (Boyle and Levin, 2008). For instance, the consequences of a study directed in Pakistani health care facilities showed that dominant part of working health experts did not have sufficient learning about the essential and auxiliary avoidance strategies for cervical disease (Ali et 
al, 2010). Besides, a study surveying social insurance supplier's learning on STIs gave destroying results. Khan, Unemo, Zaman, and Lundborg (2009) reported that just $45 \%$ of respondents had the right information about aversion and spread of HIV, and ten percent could refer to the right treatment for diseases of syphilis and vaginal release

\section{Social Perspective with Respect to Pakistani Women}

In the global south, youngsters are getting married in mature age as compared to youngsters of their previous generation (Mensch, Singh, and Casterline 2005). This phenomenon is clearly visible in Pakistan as well. Pakistan takes on the same pattern as some studies noticed that the percent of 20-24 years old married couple has diminished consistently in last fifty years (Minhaj ul Haque and Faizunnisa, 2003). Pakistan Federal Bureau of Statistics, 2010 shows that the average age of Pakistani females when they got married was $\mathbf{2 2 . 8}$ years-a time-wise relatively mature age. This pattern mirrors an expansion of six points contrasted with the 196os. Nonetheless, due to the tabooed nature of the topic of sex before marriage by the young, there is no information accessible on females' normal period of sexual exposure in Pakistan. For the most part, regional studies around there acknowledge that females are exposed to sexual interaction only after they get married. Normally, the consummation of marriage exposes females to sexual interaction for the first time.

The fact of the matter is that people do not marry early. More likely than not individuals are progressively getting married late in the present times. It is mainly because of the association between people economic stability, their employment status, security in marital life. People do not marry until they feel secured about themselves and their partners economic stability. Since people cannot find job soon after they are adult they wait for jobs. They get stable jobs very late. Meanwhile, they get involved in sexual interactions without marriage as they see no strings attached to that in terms of the requirements of financial stability. In this manner, it is proposed that premarital sexual action is spreading perhaps both as a cause and as an impact of the late relational unions. Tragically, youth's sexual conduct in Pakistan is a highly understudied phenomenon mainly because sex is a taboo for many in Pakistan and hence, collecting data on topic related to sex is difficult. Consequently, there is no information on youth involvement in sexual conduct before marriage. One study carried out among 1319 years old demonstrated that amid up close and personal meetings just 1\% of young girls said that they engaged in sexual relations; amid the unknown self-controlled interviews, there was an increase from $1 \%$ to $3 \%$ (UNICEF, 2006).

Different studies have been conducted in India as well on the same topic (e.g. Abraham, 2003; Jejeebhoy, 1998). These studies concluded that up to 10\% of youthful females have a sexual experience before marriage. In addition, a relatively recent study from Pakistan that was carried out among females of age range 18-24 years old female college-going students indicate a staggering figure of 45.6\% meaning thereby that college-going unmarried women reported extra-marital relations at the time of the survey, $78.3 \%$ of them experienced sexual activity before the age of eighteen, and on normal, the study members had 2.69 sexual accomplices (Vahe, 2012).

Different studies provide data on the involvement of youngsters in sexual interaction without marriage. Most of the studies show that the rate of Indian young citizens or Pakistani males' young citizens who had experienced sexual relationship before marriage is somewhere around 5\% and $30 \%$ (e.g., Abraham, 2003; Jejeebhoy, 1998; UNICEF, 2006). Youthful guys' sexual accomplices include more mature women (aunties), and other gender categories such as male, female or transsexual (hijras) business sex labourers, whilst these relationships and experiences take place without contraceptives (Abraham, 2003). 


\section{References}

Abraham, L. (2003). Risk behaviour and misperceptions among low-income college students of Mumbai. In S. Bott, S. Jejeebhoy, I. Shah \& C. Puri (Eds.), Towards adulthood: Exploring the sexual and reproductive health of adolescents in South Asia (pp. 73-77). Geneva: World Health Organization.

Abrejo, F. G., Shaikh, B. T., \& Saleem, S. (2008). ICPD to MDGs: Missing links and common grounds. Reproductive Health, 5(1), 4.

Adhikari, R. K. (2003). Early marriage and childbearing: risks and consequences. In S. Bott, S. Jejeebhoy, I. Shah \& C. Puri (Eds.), Towards adulthood: Exploring the sexual and reproductive health of adolescents in South Asia (pp. 62-66). Geneva: World Health Organization

Al-Oballi Kridli, S., \& Libbus, K. (2001). Contraception in Jordan: A cultural and religious perspective. International Nursing Review, 48, 144-151.

Ali, S. A., Ali, P. A., Waheed, H., \& Memon, A. A. (2006). Understanding of puberty and related health problems among female adolescents in Karachi, Pakistan. The Journal of Pakistan Medical Association, 56(2), 68-72.

Barnett, B., \& Schueller, J. (2000). Meeting the needs of young clients: A guide to providing reproductive health services to adolescents. Retrieved from http://www.fhi.org/en/RH/Pubs/servdelivery/adolguide/index.htm.

Bott, S., \& Jejeebhoy, S. J. (2003). Adolescent sexual and reproductive health in South Asia: An overview of findings from the 2000 Mumbai conference. In S. Bott, S. Jejeebhoy, I. Shah \& C. Puri (Eds.), Towards adulthood: Exploring the sexual and reproductive health of adolescents in South Asia (pp. 3-28). Geneva: World Health Organization.

Boyle, P. \& Levin, B. (2008). World Cancer Report, 2008. World Health Organization.

WHO Press: Geneva. Retrieved from

http://www.iarc.fr/en/publications/pdfsonline/wcr/2008/wcr_2008.pdf

Capoor, I., \& Patel, P. (2006). Adolescent and young people's issues and concerns in South Asia: Challenges ahead. CHETNA. from http://www.chetnaindia.org/FINAL\%2OPAPER\%20FOR\%20PAKISTAN.pdf.

Casterline, J. B., Sathar, Z. A., \& Minhaj ul Haque. (2001). Obstacles to contraceptive use in Pakistan: A study in Punjab. Studies in Family Planning, 32(2), 95-110.

Chowdhury, S. N. M. (2003). Pregnancy and postpartum experience among first time young parents in Bangladesh: preliminary observations. In S. Bott, S. Jejeebhoy, I. Shah \& C. Puri (Eds.), Towards adulthood: Exploring the sexual and reproductive health of adolescents in South Asia (pp. 5961). Geneva: World Health Organization.

Durrani, S. H. (2010). Pakistan's statement at the 43rd session of the Commission on Population and Development, 13 April, 2010, New York. Retrieved from http://www.un.org/esa/population/cpd/cpd2010/Country_Statements/AgendaItem4/PAKIST AN.PDF.

Faizzunisa, A., \& Ikram, A. (2004). Determinants of youth development in Pakistan. The Lahore Journal of Economics, 9(2), 119-133.

Freedman, R. (1987). The contribution of social science research to population policy and family planning program effectiveness. Studies in Family Planning, 18(2), 57-82.

Halstead, J. M., \& Lewicka, K. (1998). Should homosexuality be taught as an acceptable alternative lifestyle? A Muslim perspective. Cambridge Journal of Education, 28(1), 49-64.

Hakim, A., Uhssain, Z., Baqai, M., \& Tanweer, B. D. (2000). Perceptions of religious leaders about population welfare. Islamabad: National Institute of Population Studies.

Hardee, K., Pine, P., \& Wasson, L. T. (2004). Adolescent and youth reproductive health in the Asia and 
near East region. Status, Issues, Policies, and Programs. Policy project. Retrieved from http://pdf.usaid.gov/pdf_docs/PNACX530.pdf.

Hardee, K., \& Leahy, E. (2008). Population, fertility and family planning in Pakistan: A program in stagnation. Population Action International. Retrieved from http://www.populationaction.org/Publications/Report/Population_and_FP_in_Pakistan/pakist an.pdf.

Hoodfar, H., \& Assadpour, S. (2000). The politics of population policy in the Islamic Republic of Iran. Studies of Family Planning, 31(1), 19-34.

Khan, A. A., \& Khan, A. (2010). The HIV epidemic in Pakistan. Journal Pakistan Medical Association, $60(4), 300-307$.

Jejeebhoy, S. J. (1998). Adolescent sexual and reproductive behavior: A review of the evidence from India. Social Science and Medicine, 46(10), 1275-1290.

Jejeebhoy, S. J. \& Sathar, Z. A. (2001). Women's Autonomy in India and Pakistan: The influence of religion and region. Population and Development Review, 27(4), 687-712.

Khan, A. (1999). Mobility of women and access to health and family planning services in Pakistan. Reproductive Health Matters, 7(14), 39-48.

Khan, A., \& Pine, P. (2003). Adolescent and youth reproductive health in Pakistan. Status, Issues, Policies, and Programs. Retrieved from http://www.policyproject.com/pubs/countryreports/ARH_Pakistan.pdf

Khan, S. K., Unemo, M., Zaman, S., \& Lundborg, C. S. (2009). Knowledge, attitudes and practices regarding human immunodeficiency virus/acquired immune deficiency syndrome and sexually transmitted infections among health care providers in Lahore, Pakistan. Journal of Ayub Medical College, Abbottabad, 21(4), 1-6.

Lorimer, F. (1954). Culture and human fertility: A study of the relation of cultural conditions to fertility in non-industrial and transitional societies. Paris: UNESCO.

Mensch, B. S., Singh, S., \& Casterline, J. B. (2005). Trends in the timing of first marriage among men and women in the developing world. Population Council. Retrieved from http://www.popcouncil.org/pdfs/wp/202.pdf.

Mouli, V. C. (2003). Adolescent-friendly health services. In S. Bott, S. Jejeebhoy, I. Shah \& C. Puri (Eds.), Towards adulthood: Exploring the sexual and reproductive health of adolescents in South Asia (pp. 195-198). Geneva: World Health Organization.

Minhaj ul Haque \& Faizunnisa, A. (2003). Access to reproductive health information in Punjab and Sindh, Pakistan: The perspectives of adolescents and parents. In S. Bott, S. Jejeebhoy, I. Shah \& C. Puri (Eds.), Towards adulthood: Exploring the sexual and reproductive health of adolescents in South Asia (pp. 153-155). Geneva: World Health Organization.

Omran, A. R. (1992). Family planning in the legacy of Islam. London and New York: Routledge.

Pakistan Federal Bureau of Statistics (2010). Compendium on gender statistics of Pakistan 2009. Retrieved from http://www.statpak.gov.pk/fbs/sites/default/files/social_statistics/publications/cgs2009/COM PENDIUM\%20GENDER\%20STATISTICS\%202009.pdf.

Pakistan Ministry of Population Welfare. (2002). National Population Policy 2002. Retrieved from http://www.scribd.com/doc/48605557/population-policy-2002

Pakistan Ministry of Population Welfare. (2010). National Population Policy 2010. Retrieved from http://www.scribd.com/doc/3402296o/Pakistan-Population-Policy.

Ranjha, S. M., \& Hussain, A. (2003). Sexual health services for adolescents at sex clinics in Rawalpindi, Pakistan. In S. Bott, S. Jejeebhoy, I. Shah \& C. Puri (Eds.), Towards adulthood: Exploring the sexual and reproductive health of adolescents in South Asia (pp. 148-150). Geneva: World Health Organization. 
Raza, S. A., Franceschi, S., Pallardy, S., Malik, F. R., Avan, B. I., Zafar, A.,..., Clifford, G. M. (2010). Human papillomavirus infection in women with and without cervical cancer in Karachi, Pakistan. British Journal of Cancer, 102, 1657-166o.

Sathar, Z. A., Minhaj ul Haque, Faizunnissa, A., Sultana, M., Lloyd, C. B., Diers, J. A., \& Grant, M. (2003). Adolescents and youth in Pakistan 2001-02: A nationally representative survey. Retrieved from http://www.popcouncil.org/pdfs/ayp0102.pdf.

Sathar, Z. A., Singh, S., \& Fikree, F. F. (2007). Estimating the incidence of abortion in Pakistan. Studies in Family Planning, 38(1), 11-22.

Seltzer, J. R. (2002). The origins and evolution of family planning programs in developing countries. Santa Monica: RAND.

Senderowitz, J. (1999). Making reproductive health services youth friendly. Focus on young adults. Retrieved from http://info.k4health.org/youthwg/PDFs/Focus/KeyElementsPapers/makingRHservicesyouthfr iendly.pdf.

Siddh, K. K. (1974). Family planning: The religious factor. New Dehli: Anhinav Publications.

UNICEF. (2006). Situation assessment of adolescents for life skills and HIV prevention in selected districts of Pakistan. $\quad$ Retrieved from http://www.unicef.org/pakistan/Situation_Assessment_Report.pdf.

United Nations. (1995). Report of the International Conference on Population and Development. Cairo, 5-13 September 1994. Retrieved from http://www.unfpa.org/webdav/site/global/shared/documents/publications/2004/icpd_eng.pdf

UNFPA. [United Nations Population Fund]. (2008). Culture matters: Lessons from a legacy of engaging faith-based $\quad$ organizations. Retrieved from http://www.unfpa.org/webdav/site/global/shared/documents/publications/20o8/Culture_Matt er_II.pdf.

Vahe, M. (2012). Human Papillomavirus awareness, knowledge and information sources among young female adults in conservative developing countries: The case of Pakistan. Paper presented at the Kentucky Conference on Health Communication: Health Literacy Research and Practice. Lexington, $\mathrm{KY}$.

World Bank. (2011). Reproductive health at a glance: Pakistan. Retrieved from http://siteresources.worldbank.org/INTPRH/Resources/3763741303736328719/Pakistan42211w eb.pdf

WHO. [World Health Organization]. (2010b). Human papillomavirus and related cancers. Pakistan. Retrieved from http://apps.who.int/hpvcentre/statistics/dynamic/ico/country_pdf/PAK.pdf?CFID=4678474\& $\mathrm{CFTOKEN}=56928517$. 